\title{
Compreendendo a comunidade: experiência da equipe interdisciplinar do Bom Jardim - Fortaleza (CE)
}

Case Repomt

\author{
Understanding the community: the experience of the \\ interdisciplinary team of Bom Jardim - Fortaleza, Ceará
}

Larissa de Fátima Pontes Aguiar ${ }^{1}$ Érica Nobre Lima²

Lidiany Alexandre Azevedo ${ }^{3}$

Meiryline Gomes Lira ${ }^{4}$

Marcel Jofran Ramalho Martildes ${ }^{5}$

Ana Ester Maria Melo Moreira ${ }^{6}$

Ivana Cristina de Holanda Cunha Barreto ${ }^{7}$

\section{Resumo}

O presente trabalho objetiva sistematizar o relato de experiência da equipe de estudantes do Projeto de Extensão Liga de Saúde da Família inserida na comunidade do Bom Jardim, em um município de Fortaleza. Os estudantes de cursos de graduação da área de saúde constituem uma equipe interdisciplinar e trabalham acompanhados por um facilitador experiente em trabalho comunitário, partindo das seguintes bases teóricas e metodológicas: educação popular em saúde, promoção da saúde, saúde da família, psicologia comunitária. Este referencial potencializou a construção compartilhada do conhecimento entre o saber popular e o saber científico partindo da inserção comunitária dos estudantes na comunidade. Esta experiência tem potencializado a inflexão da formação dos estudantes envolvidos, agregando saberes e práticas complexas de leitura e da realidade e atuação em um grande bairro da periferia de Fortaleza.

\section{Abstract}

The present study aims at systematizing the report of the experience of a team of students participating in the Extended Project "League of Family Health" in the community of Bom Jardim, city of Fortaleza. Undergraduate students from the health area form an interdisciplinary team working under the guidance of a facilitator, expert in community work. The theoretical and methodological bases of their work are: health education for the community, health promotion, family health, community psychology. This theoretical reference improved the construction of shared popular and scientific knowledge as a result of the participation of the students in the community. This experience improved the students' communication and relationship skills and helped them to acquire the knowledge and practice necessary for reading the

Palavras-chave: Relações interprofissionais; Participação

Comunitária; Saúde da Família; Equipe de Assistência

ao Paciente; Educação em Saúde; Promoção da Saúde.
Key Words: Interprofessional Relations; Consumer Participation; Family Health; Patient Care Team;

Health Education; Health Promotion.

${ }^{1}$ Estudante de Enfermagem integrante do PELSF, Universidade Federal do Ceará, Fortaleza, Ceará, Brasil.

${ }^{2}$ Estudante de Odontologia integrante do PELSF, Universidade Federal do Ceará, Fortaleza, Ceará, Brasil.

${ }^{3}$ Estudante de Psicologia integrante do PELSF, Universidade Federal do Ceará, Fortaleza, Ceará, Brasil.

${ }^{4}$ Estudante de Gestão Hospitalar da FIC e integrante do PELSF, Universidade Federal do Ceará, Fortaleza, Ceará, Brasil.

${ }^{5}$ Estudante de Medicina e integrante do PELSF, Universidade Federal do Ceará, Fortaleza, Ceará, Brasil.

${ }^{6}$ Psicóloga, mestranda em Saúde Pública da UFC e facilitadora do PELSF, Secretaria Municipal de Saúde de Fortaleza, Fortaleza, Ceará, Brasil.

${ }^{7}$ Médica. Professora adjunta, Faculdade de Medicina, Universidade Federal do Ceará, Fortaleza, Ceará, Brasil. 
complex reality and working in a big neighborhood on the periphery of Fortaleza.

\section{Introdução}

A atividade extensionista pode tanto caminhar no sentido de questionar a ordem estabelecida, produzindo novas práticas e novos saberes impulsionadores de uma mudança social, como dar subsídio à contextualização e ao desenvolvimento de pesquisa e de ensino também comprometidos com questões sociais.

A Constituição Brasileira de 1988, em seu artigo 200 inciso III, define que ao SUS, além de outras atribuições, compete ordenar a formação de recursos humanos na área da saúde. A Lei nº 8080 (Lei Orgânica da Saúde) descreve em seu parágrafo único que os serviços públicos que integram o SUS constituem campo de práticas para o ensino e a pesquisa. ${ }^{1}$

O Projeto de Extensão Liga de Saúde da Família (LSF) nasceu da necessidade de construção de práticas interdisciplinares com estudantes de graduação, calcadas no princípio da integralidade e na Estratégia de Saúde da Família, assim como do desejo de professores e estudantes da UFC e técnicos da Secretaria Municipal de Saúde de Fortaleza (SMSE) de contribuir neste processo.

Os referenciais teórico-metodológicos que passaram a orientar o LSF a partir de sua criação foram: educação permanente em saúde, educação popular em saúde, trabalho em equipe multiprofissional e interdisciplinar, Estratégia de Saúde da Família (ESF), promoção de saúde e psicologia comunitária ${ }^{2}$.

O Núcleo inicial de organizadores do projeto foram professores dos cursos de Medicina, Enfermagem, Psicologia, Odontologia, Farmácia e Educação Física da Universidade Federal do Ceará e técnicos em Educação Permanente da Secretaria Municipal de Saúde de Fortaleza. Posteriormente, professores e estudantes da Faculdade Integrada do Ceará (FIC) associaram-se ao grupo. A proposta foi de constituir equipes multiprofissionais de estudantes de cursos de graduação em saúde e inseri-las no Centro de
Saúde da Família e no território de atuação de sete diferentes equipes de saúde da família de Fortaleza.

O projeto se propõe permitir ao estudante vivenciar o contexto de trabalho das equipes de saúde da família a partir do princípio da integralidade inseridos no território vivo de atuação da saúde da família, que consiste nos espaços social, cultural, simbólico, afetivo e físico. As equipes de estudantes trabalham em uma determinada comunidade acompanhando, reconhecendo e realizando um mapeando social dos grupos comunitários existentes, estimulando a organização de novos grupos e desenvolvendo facilitação social das potencialidades locais de trabalho em saúde, principalmente no campo da promoção de saúde ${ }^{3}$. Cada equipe é acompanhada por um facilitador, profissional da área da saúde, com experiência na ESF.

Justificamos o presente trabalho pela relevância de divulgar para outras Universidades e Secretarias Municipais de Saúde uma experiência bem-sucedida de inserção de estudantes na ESF. Nosso objetivo foi descrever o processo de inserção comunitária e atuação da equipe de estudantes e fa- cilitadores da LSF do bairro Bom Jardim.

O Grande Bom Jardim, lócus da experiência, está localizado a sudoeste de Fortaleza (CE), na Secretaria Executiva Regional V, fazendo fronteira com os municípios de Caucaia e Maracanaú. Consiste em um complexo populacional de 18.700 hectares de extensão, que abrange cinco bairros: Granja Lisboa, Granja Portugal, Canindezinho, Siqueira e Bom Jardim. A população total do Grande Bom Jardim é de 175 mil habitantes, sendo a faixa etária predominante de jovens ${ }^{4}$.

A população residente no bairro, em sua maioria, tem renda média baixa ou baixa e sofre problemas que dizem respeito à qualidade e à legalização das residências. As principais atividades geradoras de renda são pequenos comércios que funcionam ao longo de uma das avenidas principais.

As instituições governamentais existentes são Casa Brasil, Centro Cultural Bom Jardim, Centro de Referência de Assistência Social, um Centro de Atenção Psicossocial (CAPS) e dois Centros de Saúde da Família. A região conta 
com 47 escolas públicas municipais e estaduais, 103 escolas particulares e duas escolas comunitárias. Existem também dezenas de ONGs ${ }^{5}$. Há uma carência de equipamentos de lazer e muitos dos que existem estão em situação precária para utilização.

\section{Desenvolvimento}

Somos uma equipe composta por estudantes dos cursos de saúde de Medicina, Enfermagem, Odontologia e Psicologia da UFC e por uma aluna de gestão hospitalar da Faculdade Integrada do Ceará (FIC).

Nosso primeiro contato com a comunidade do Bom Jardim se deu durante a realização do II Escambo de Arte e Cultura realizado na Escola Municipal Lireda Facó, o qual foi promovido pelo projeto Cirandas da Vida da SMSF em parceria com o Movimento de Saúde Mental Comunitária do Bom Jardim (MSMCBJ), o Espaço Geração Cidadã e o grupo Consciência Break. $O$ evento foi caracterizado por músicas, danças, apresentações dos grupos locais de capoeira e hip-hop.

Neste primeiro momento, utilizamos a metodologia de observação participante ${ }^{6}$, que continuou sendo empregada durante todo o processo de inserção. Foi possível, então, visualizarmos a importância dos movimentos de arte e cultura naquela comunidade, a partir da grande adesão da população local nas atividades, bem como a relevância da educação popular que existia por meio desses movimentos.

Porém, é importante ressaltarmos que nas primeiras semanas de trabalho surgiram os sentimentos de curiosidade e ansiedade no grupo, pois estávamos descobrindo uma realidade diferente da que estávamos habituados a experimentar como universitários, mais teórica, racional e menos complexa. Surgiram também questionamentos e inseguranças de como agir na comunidade.

Com a problematização da facilitadora, entendemos o processo de inserção como uma construção coletiva que envolvia tanto nossa equipe como a própria comunidade. Demos continuidade às nossas atividades por meio de caminhadas no bairro, pois acreditávamos que vivenciar questões do dia-a-dia nos ajudaria a perceber os elementos mais profundos do local. Discutimos com a facilitadora e a professora sobre a importância de se ter dois olhares a cerca da comunidade; como nos diz Montero por meio da metáfora do bosque, quem está dentro ou totalmente perdido na comunidade não consegue enxergar a sua magnitude, só vê o superficial, só sabe que está dentro dele, sendo incapaz de conhecer suas dimensões e características, já as descrições de quem está fora carecem das vivências, do contato estreito com a realidade ${ }^{7}$. Dessa maneira, compreendemos que, na nossa observação, necessitaríamos ter estes dois olhares, o de dentro e o de fora, a fim de melhor entender a comunidade.

Nessas caminhadas, percorremos distintos locais do bairro, conversamos com os moradores e visitamos alguns projetos e instituições. Observamos em parte da população a ocorrência de doenças infecciosas (tuberculose e hanseníase), o consumo elevado de bebidas alcoólicas, a falta de recursos básicos, baixa escolaridade, desemprego, violência, falta de perspectivas de futuro e um sentimento de abandono por parte das autoridades. Alguns moradores verbalizaram que os políticos e lideranças só freqüentavam a comunidade na época das eleições.

Outro aspecto que foi percebido é que os moradores desconheciam grande parte dos projetos já existentes na comunidade. Além disso, as pessoas diretamente responsáveis pelos projetos também desconheciam os outros projetos que havia ali, os quais muitas vezes realizavam o mesmo tipo de ação. Constituíram exceção o MSMCBJ e o CAPS. Compreendemos então a importância de tentar estabelecer uma articulação entre essas organizações a fim de que as atividades fossem mais bem divulgadas junto à população de forma a aumentar o seu impacto.

Dentre os equipamentos sociais que visitamos estavam: o MSMCBJ, que entende o ser humano na sua dimensão biopsicossocioespiritual e trabalha desenvolvendo seus potenciais por meio de valores humanos e da arte e cultura. O MSMCBJ oferece grupos de terapia comunitária e os projetos Sim à Vida Não às Drogas, Casa de Aprendizagem Ezequiel Ramin, Horta Comunitária, Centro de 
Aprendizagem do Bom Jardim, além de estabelecer uma parceria com o CAPS. Travamos também conhecimento com o Centro de Saúde da Família Argeu Herbest (CSFAH), que conta com três equipes do Programa de Saúde da Família (PSF). O CSFAH organiza também grupos de Terapia Comunitária. Outras instituições que visitamos foram: a Pastoral da Criança e o Projeto Batista Nova Aliança.

Durante nossa caminhada no Grande Bom Jardim, criamos vínculo com vários grupos comunitários: o MSMCBJ, os agentes comunitários de saúde e os conselheiros locais de saúde.

Uma das rodas de conversa que realizamos com as lideranças da comunidade foi de grande relevância, pois, por meio da fala dos moradores, conhecemos a sua história de luta e resistência. Descobrimos que o movimento popular encontra-se enfraquecido, pois as pessoas não estão se apropriando das lutas da comunidade.

Como resultado de todo esse processo de comunicação, participação e reflexão, foi então traçada a realização de uma Oficina de Resgate da História de Luta e Resistência do Bom Jardim com a participação da comunidade. A Oficina ocorreu no PETI (Programa de Erradicação do Tra- balho Infantil) situado no bairro Urucutuba - Bom Jardim. Iniciou-se com um momento de apresentação dos Tambores do MSMCBJ, articulado pelo Projeto Cirandas da Vida. O ritmo dos tambores foi envolvendo todos que estavam presentes, despertando também o interesse dos moradores próximos do local, que logo foram fazendo parte desse encontro de reflexão com base na educação popular e na participação social. Em seguida, houve o momento de nossa apresentação para comunidade, quando expusemos nossos objetivos no território. A seguir, dividiram-se as pessoas em três grupos geracionais: o grupo das crianças, facilitado pela estudante de Enfermagem Larissa; o grupo dos jovens, facilitado pelo estudante de Medicina Marcel, e o grupo dos adultos, pela estudante de Odontologia Érica e a estudante de Gestão Hospitalar Meiryline.

$\mathrm{Na}$ metodologia utilizada pelo grupo de crianças, iniciou-se com a distribuição de crachás, como uma forma diferenciada de apresentação. A seguir, foi ensinada uma cantiga de roda: "Olelé, olalá, uma história eu vou contar", sendo solicitado que a criança descrevesse o que havia próximo à sua casa, como era sua rua, se havia ocorrido alguma mudança no seu bairro. Depois se cantava novamente a música e outra criança dava seu depoimento. Pela fala das crianças - "Vizinho a minha casa só tem mato"; "Meu pai bebe demais, demais mesmo"; "No quintal da minha casa tem um terreiro" -, identificamos os seguintes temas: geração de emprego e renda, alcoolismo e espiritualidade. No momento final, as crianças retrataram no papel, com o uso de giz de cera, o desenho do seu bairro. A metodologia lúdica aplicada foi bastante enriquecedora, pois foi possível obter a concentração e participação das crianças e, ao mesmo tempo, a atividade proporcionou o prazer de brincar.

$\mathrm{Na}$ roda com os jovens, foi colocada em discussão sobre qual seria a metodologia do trabalho em grupo. Os presentes decidiram pela problematização sobre a história do bairro, baseando-se na pergunta: "O que a historia do Bom Jardim representa para você?”. Foi relatado pelos participantes que o Bom Jardim foi criado por um grande processo migratório de sertanejos cearenses fugindo da seca, proveniente do sertão central. Estes migrantes, a partir de invasões de terra, formaram o aglomerado urbano inicial. Com a organização comunitária e o incentivo da igreja católica (Comunidade Eclesiais de Base e Combonianos), iniciou-se a luta por ações efetivas do poder público na comunidade. No grupo dos adultos foram abordadas problemáticas que influenciaram no surgimento do Bom Jardim e que marcaram sua história até o momento atual. Foi colocada em questão a falta de informação dos moradores com relação às redes sociais presentes na comunidade, dificuldades em articular a comunidade para tomada de decisões coletivas.

Segundo os participantes, os movimentos sociais surgiram a partir da necessidade de construir uma rede de articulação entres os diversos grupos comunitários. Por meio de muitas lutas foi se conquistando espaços políticos e serviços públicos. Foi criado o Conselho Local de Saúde, construíram-se creches, e uma conquista considerada muito importante pelos presentes, que foi a construção do Centro 
de Saúde da Família Abner Cavalcanti. Nos primeiros anos da ocupação não havia assistência à saúde para os moradores. Ao longo do tempo foram surgindo os grupos sociais que começaram a assumir um papel relevante na vida dos moradores do Bom Jardim, tais como: MSMCBJ, o Sopão, o Centro Regional de Assistência Social, o Grupo dos Idosos e muitos outros.

Com o fim dos grupos de discussão, ocorreu a apresentação dos resultados e o debate na plenária. Nesse momento ficou evidente a diferença dos pensamentos e visões da realidade de cada grupo geracional, demonstrando a necessidade de integração de toda a comunidade em tomo de objetivos comuns. No fim do debate a arte e a cultura popular, por meio dos tambores, produziram um momento de vivência e reflexão sobre a realidade.

Nós consideramos que a oficina foi bastante produtiva, pois houve troca do saber popular e do saber cientifico através do diálogo e mediada também pela linguagem da arte. O Projeto Cirandas da Vida foi bastante importante na construção metodológica deste momento, fortalecendo o vínculo entre a equipe da Liga de Saúde da Família e a comunidade do Bom Jardim.

Nós continuamos desenvolvendo nossa caminhada no Bom Jardim a partir da proposta do plano de atuação que foi construído coletivamente e de forma compartilhada com a comunidade e os profissionais de saúde.

\section{Conclusão}

O presente trabalho desenvolveu a construção de uma equipe interdisciplinar de estudantes de graduação de saúde, atuando no contexto da saúde da família e avançando no desenvolvimento do trabalho comunitário, no qual o território é espaço de aprendizagem coletiva. Nossa construção foi desenvolvida por um referencial teórico-metodológico participativo e problematizador da realidade, o que inicialmente gerou angústia e insegurança da equipe, pois o plano de trabalho deveria partir da realidade comunitária e do nosso protagonismo como equipe. As rodas de discussão teóricas e operativas foram permitindo um processo de reflexão-ação para transformar a realidade em uma perspectiva freiriana. Os grupos populares e os profissionais de saúde, por intermédio dos agentes comunitários, foram um elemento facilitador, potencializando a nossa inserção comunitária e o desenvolvimento de trabalho no território. Nossa equipe tem compreendido a importância do trabalho na atenção primária em saúde, mais especificamente no contexto da estratégia da saúde da família, partindo de uma base comunitária de forma dialógica e participativa. A formação em tradicional das graduações em saúde não tem permitido esta experiência. A Extensão Universitária, desta forma, constitui-se em uma possibilidade para o desenvolvimento de nossa capacidade de iniciativa, trabalho em equipe, comunicação e organização comunitária, tornando claro para nós a determinação social da saúde.

A participação de nossa equipe tem mobilizado a comunidade por meio de rodas e oficinas de encontro dos grupos populares, fortalecendo o trabalho articulado dos agentes comunitários de saúde, do MSMCBJ e de diversas outras redes sociais da comunidade.

O Projeto de Extensão Liga de Saúde da Família atua no fortalecimento da co-construção da autonomia de todos os atores envolvidos no processo: estudantes, professores, comunidade e profissionais de saúde.

\section{Referências}

1. Brasil. Lei Orgânica da Saúde número 8080 de 19 de setembro de 1990. Disponível em: http://www.soleis.adv .br/leiorganicadasaude.htm, acesso em 15 de abril de 2008. 2. Barreto ICHC. et al. Projeto de Extensão Liga de Saúde da Família, Pró-reitoria de Extensão, Coordenadoria de Ação Social Comunitária. Fortaleza (CE): Universidade Federal do Ceará; 2007.

3. OPAS. Primeira Conferência Internacional sobre Promoção da Saúde, Ottawa ,1986. Disponível em: http://www. opas.org.br/promocao/uploadArq/Ottawa.pdf acesso em 14 de abril de 2008.

4. Instituto Brasileiro de Geografia e Estatística. Disponível em: http://www.sidra.ibge.gov.br/bda/tabela/prota bl.asp? $\mathrm{z}=\mathrm{t} \& \mathrm{o}=4 \& \mathrm{x}=\mathrm{P}$ acesso em 13 de abril de 2008 . 
5. Brandão CR. Pesquisa Participante. São Paulo: Brasiliense; 1984.

6. Góis CWL. Psicologia Comunitária: atividade e consciência. Fortaleza (CE): Instituto Paulo Freire; 2005.

7. Saúde Comunitária: pensar e fazer. São

Paulo. Editoria HUCITEC, 2008.

Apoio Institucional: Universidade Federal do Ceará e Secretaria Municipal de Saúde de Fortaleza

\section{Endereço para correspondência:}

Rua Leonardo Mota, 2000, apto. 601.

Fortaleza - CE

\section{Endereço eletrônico:}

laladefatima@gmail.com. 